\title{
Experimental challenge of bovine mammary glands with Enterococcus faecium during early and late lactation ${ }^{1}$
}

\author{
C. S. Petersson-Wolfe, S. L. Wolf, and J. S. Hogan ${ }^{2}$ \\ Department of Animal Sciences, The Ohio State University, Ohio Agricultural Research and Development Center, Wooster 44691
}

\section{ABSTRACT}

Mammary glands of early and late lactation cows were challenged with Enterococcus faecium of bovine origin to determine in vivo pathogenicity and milk somatic cell count (SCC) responses. A total of 20 early lactation and 18 late lactation mammary glands were challenged. Two isolates highly adaptive and 2 isolates poorly adaptive for in vitro growth in mammary secretion were used as challenge strains of bacteria. Challenged quarters of early lactation cows were more susceptible to intramammary infection caused by E. faecium than those of late lactation cows. Intramammary challenge with isolates poorly adaptive for in vitro growth in mammary secretions resulted in $94.7 \%$ of quarters infected compared with $36.8 \%$ of the quarters infused with the isolates highly adaptive for in vitro growth in mammary secretions. Milk from quarters infused with the isolates poorly adaptive for in vitro growth had higher SCC and bacterial counts compared with quarters challenged with the isolates highly adaptive for in vitro growth. A stage of lactation effect within treatment groups was measured when milk SCC were compared between early and late lactation cows. Milk SCC in uninfused (negative control) quarters were lower in early lactation cows compared with late lactation cows. Conversely, in quarters infused with isolates poorly adaptive for in vitro growth, SCC were higher in early lactation cows compared with late lactation cows on d 2, 3, 4, 15, 16, and 17 postchallenge. In quarters infused with isolates highly adaptive for in vitro growth, SCC response did not differ between early and late lactation cows. In vitro growth of E. faecium in mammary secretion was inversely related to in vivo pathogenicity in the mammary glands of early and late lactation cows.

Key words: Enterococcus faecium, intramammary challenge, infection

Received September 26, 2008.

Accepted February 23, 2009.

${ }^{1}$ Salaries and research support were provided by state and federal funds appropriated to the Ohio Agricultural Research and Development Center, The Ohio State University Manuscript Number 21-08AS.

${ }^{2}$ Corresponding author: hogan.4@osu.edu

\section{INTRODUCTION}

Enterococcus species are of profound importance as etiological agents of enteric diseases in humans (NNIS Report, 1997; Edwards, 2000), companion animals (Jergens et al., 1991; Helie and Higgins, 1999), and foodproducing animals (Rogers et al., 1992; Teixeira et al., 2001). Inherent and acquired antimicrobial resistance displayed by enterococci were proposed as characteristics facilitating the persistence of these pathogens within host populations and survival in the environment (Murray, 1990). In addition to the importance of enterococci as an enteric pathogen in other species, these bacteria are a known cause of bovine mastitis. Reports suggest enterococci were the causative agent in 8 to $13 \%$ of all bovine IMI (Aleksieva and Todorov, 1981; Gianneechini et al., 2002). Moreover, 24 to $30 \%$ of IMI classified as environmental streptococcal infections were caused by enterococci (McDonald and McDonald, 1976; Devriese et al., 1999). A nonrandomized survey estimated that enterococci represent $42.7 \%$ of environmental streptococci isolates (Petersson-Wolfe, 2006). The predominant species of enterococci isolated from postpartum milk samples, cows with elevated composite milk SCC, and clinical mastitis was Enterococcus faecium (Petersson-Wolfe, 2006).

Experimental intramammary challenge studies have been conducted to examine the dynamics of bovine IMI including cytological responses occurring following pathogen invasion. Some examples include the expression of cell surface markers (Rivas et al., 2001) and neutrophil apoptosis (Sladek et al., 2005) following Staphylococcus aureus challenge. In addition, susceptibility of cows in differing stages of lactation (Shuster et al., 1996) and the correlation between neutrophil viability and the severity of coliform mastitis (Mehrzad et al., 2004) were examined. Intramammary challenge trials were utilized to test the efficacy of mastitis vaccines against Streptococcus uberis (Hill et al., 1994), as well as leukocyte recruitment following infusion (Rambeaud et al., 2003). Controlled experimental challenge trials have provided useful information over many decades regarding the kinetics of IMI and the host response during different stages of lactation. Despite the profound effect 
Table 1. Selection characteristics of 4 Enterococcus faecium isolates used for intramammary challenge of early and late lactation mammary glands

\begin{tabular}{|c|c|c|c|c|}
\hline \multirow[b]{2}{*}{ Isolate } & \multirow[b]{2}{*}{ In vitro growth ${ }^{1}$} & \multirow[b]{2}{*}{ Origin $^{2}$} & \multicolumn{2}{|c|}{ Quarters challenged, $\mathrm{n}$} \\
\hline & & & Early lactation & Late lactation \\
\hline 67 & Poorly adaptive & Clinical mastitis & 6 & 5 \\
\hline 163 & Highly adaptive & Clinical mastitis & 6 & 5 \\
\hline 186 & Poorly adaptive & Postpartum & 4 & 4 \\
\hline 314 & Highly adaptive & Postpartum & 4 & 4 \\
\hline
\end{tabular}

${ }^{1}$ Challenge isolates were selected based on growth in mammary secretion after $24 \mathrm{~h}$ incubation at $37^{\circ} \mathrm{C}$ whereby in vitro growth $>5.0 \log _{10} \mathrm{cfu} / \mathrm{mL}=$ highly adaptive isolates; and in vitro growth $<2.0 \log _{10} \mathrm{cfu} / \mathrm{mL}=$ poorly adaptive.

${ }^{2}$ Isolates originated from postpartum milk samples collected at a commercial dairy and from clinical mastitis milk samples submitted to a mastitis diagnostic laboratory (Wooster, $\mathrm{OH}$ ).

that enterococci have on udder health and the lack of information regarding the pathogenicity of this organism in the mammary gland, limited data concerning enterococcal challenge studies have been reported.

Isolates for experimental intramammary challenge trials have been chosen based upon in vivo growth characteristics in bovine mammary secretions (Lohuis et al., 1990; Todhunter et al., 1990). Petersson-Wolfe et al. (2007) recently reported that in vivo growth of E. faecium was enhanced in early lactation secretions compared with late and extended lactation secretions. Those authors suggested that differences among in vitro growth responses of isolates might be related to in vivo pathogenicity of E. faecium during lactation. Therefore, the objectives of the current trial were to determine 1) the physiologic effects of E. faecium in early and late lactation cows following intramammary challenge; and 2) determine the relationship between in vitro growth in bovine mammary secretions and in vivo pathogenicity of E. faecium in the mammary gland.

\section{MATERIALS AND METHODS}

\section{Animals}

Nineteen lactating Holstein cows in the Ohio Agricultural Research and Development Center (Wooster, $\mathrm{OH}$ ) dairy herd were used in the study. Animals in early $(\mathrm{n}=$ $10)$ and late $(\mathrm{n}=9)$ lactation were enrolled. Early lactation cows averaged 27.5 DIM (range 14-44 DIM), and late lactation cows averaged 267.1 DIM (range 260-274 DIM). All animals were housed in individual tie stalls and feed was delivered daily as a TMR. All cows were milked twice daily at 12 -h intervals in a parlor.

Quarter milk samples were aseptically collected 7, 5 , and $3 \mathrm{~d}$ before date of intramammary challenge to determine infection status. Samples were evaluated for microbiological status and SCC. Specific procedures regarding quarter milk sampling, microbiological culture, and determining milk SCC were as described previously (Hogan et al., 1999).

\section{Intramammary Challenge}

Enterococcus faecium isolates used for intramammary challenge originated from postpartum milk samples collected at a commercial dairy $(\mathrm{n}=2)$ and from clinical mastitis milk samples submitted to a mastitis diagnostic laboratory $(\mathrm{n}=2)$ (Table 1$)$. Isolates were tested for growth in a pooled source of mammary secretions from 4 stages of lactation following previously reported procedures (Petersson-Wolfe et al., 2007). Challenge isolates were selected based on growth in mammary secretion whereby 2 isolates highly adaptive for in vitro growth (in vitro growth $>5.0 \log _{10} \mathrm{cfu} / \mathrm{mL}$ after $24 \mathrm{~h}$ of incubation at $37^{\circ} \mathrm{C}$ ) and 2 isolates poorly adaptive for in vitro growth (in vitro growth $<2.0 \log _{10} \mathrm{cfu} / \mathrm{mL}$ after $24 \mathrm{~h}$ of incubation at $37^{\circ} \mathrm{C}$ ) were chosen. Challenge suspensions were prepared by culturing bacteria in trypticase soy broth at $37^{\circ} \mathrm{C}$ for $18 \mathrm{~h}$. The bacterial culture was centrifuged and the pellet diluted in PBS to achieve a final concentration of approximately $1.0 \times$ $10^{4} \mathrm{cfu} / \mathrm{mL}$ in PBS. Colony-forming units of challenge inoculum were determined by delivering four $10-\mu \mathrm{L}$ replicates on the surface of a plate containing trypticase soy agar plus $0.05 \%$ ferric ammonium citrate.

A total of 38 quarters (2 contralateral quarters per cow) were challenged with enterococci in early or late lactation. An uninfected quarter of each cow was infused with an isolate highly adaptive for in vitro growth and a second contralateral uninfected quarter was infused with an isolate poorly adaptive for in vitro growth. Mammary quarters with a pre-existing natural IMI were not used in the experiment. Before infusion, challenge teats were cleaned with cotton swabs soaked in $70 \%$ ethanol. An inoculum of $1 \mathrm{~mL}$ (approximately $\left.1.0 \times 10^{4} \mathrm{cfu}\right)$ of the bacterial suspension was infused into the mammary quarter using a sterile 1-mL syringe 
fitted with a sterile teat cannula (Jorgensen Laboratories Inc., Loveland, CO). Teats were dipped with an iodophore teat disinfectant immediately following infusion. The remaining 2 quarters of each cow were nonchallenged controls. Assignment of quarters and isolates were random within cow with the exception of 2 study animals with a pre-existing natural IMI in 1 quarter. The challenged quarters for these 2 animals were assigned as the 2 uninfected, contralateral quarters. The numbers of mammary quarters infused, by stage of lactation, for each bacterial isolate are listed in Table 1.

\section{Data Collection Postchallenge}

Quarter milk samples were aseptically collected from all quarters of all study cows on the following days postchallenge: d $0,1,2,3,4,7,8,9,10,11,14,15$, $16,17,18$, and 21 . Clinical status of all quarters was recorded on a 5-point scale at the time quarter foremilk samples were obtained: $1=$ normal milk and normal quarter, $2=$ normal quarter but milk was questionable, $3=$ normal quarter but abnormal milk, $4=$ a swollen quarter and abnormal milk, and $5=$ swollen quarter, abnormal milk, and systemic signs of infection. A challenge quarter was considered clinically mastitic if the milk appearance and mammary gland scored $\geq 3$.

Detection of enterococci in challenged quarters was by duplicate $1.0-\mathrm{mL}$ pour plates using trypticase soy agar plus $0.05 \%$ ferric ammonium citrate. Total counts (cfu) were calculated by either pour plates or serial dilution of milk samples plated on the surface of trypticase soy agar plus $0.05 \%$ ferric ammonium citrate. Plates were incubated $\left(37^{\circ} \mathrm{C}, 18 \mathrm{~h}\right)$ aerobically before count determination. Total bacterial numbers were expressed as $\log _{10}$ colony-forming units per milliliter. An enterococcal IMI was defined as the isolation of $\geq 1 \mathrm{cfu} /$ $\mathrm{mL}$ of enterococci from a challenged quarter in 2 out of 3 consecutive samples. Somatic cell counts were determined on all quarter milk samples using a SomaCount 150 (Bentley, Chaska, MN). Secretions from mammary glands with clinical signs were diluted 10-fold in sterile PBS before analysis for SCC. Somatic cell counts were expressed as SCC $\log _{10}$ per milliliter.

\section{Statistical Analyses}

Descriptive statistics were derived using the frequency procedure in SAS (version 9.1, SAS Institute Inc., Cary, NC). The analysis of SCC and bacterial numbers were performed using PROC MIXED in SAS with a repeated measures approach. The appropriate error structure was assessed and used for each outcome variable. All stage of lactation and in vitro growth re- sponse in mammary secretion 2-way interaction terms were tested for significance. For each model, least squares means and standard errors were determined for significant variables. Significance was considered at $P$ $\leq 0.05$. To adjust for multiple comparisons within each model, Tukey's adjusted $P$-values were calculated for each variable.

\section{RESULTS}

The average number of bacteria infused at challenge was $1.24 \times 10^{4} \mathrm{cfu}\left(\right.$ range $1.02 \times 10^{4}$ to $\left.1.36 \times 10^{4}\right)$. No significant differences were found among isolates in the challenge inoculum. An interaction effect was observed between in vitro growth responses of isolates and stage of lactation of challenged quarters on the prevalence of IMI following challenge. Intramammary challenge with isolates poorly adaptive for in vitro growth resulted in 94.7\% (18/19) of quarters becoming infected compared with $36.8 \%$ (7/19) of quarters challenged with isolates highly adaptive for in vitro growth. The percentage of total quarters with IMI after challenge was $80 \%(16 / 20)$ in early lactation cows compared with $50 \%(9 / 18)$ in late lactation cows. In quarters challenged with isolates highly adaptive for in vitro growth, late lactation cows were diagnosed with IMI in $11.1 \%(1 / 9)$ of quarters compared with $60 \%(6 / 10)$ of quarters in early lactation cows. In contrast, percentages of quarters becoming infected following challenge with isolates poorly adaptive for in vitro growth were comparable between cows in early $(100 \%, 10 / 10)$ and late $(88.9 \%, 8 / 9)$ cows. The percentage of quarters diagnosed with IMI following challenge that showed clinical signs was $88.0 \%(22 / 25)$ and did not differ between stages of lactation or in vitro growth responses of isolates.

\section{Bacterial Counts}

In mammary quarters challenged with isolates poorly adaptive for in vitro growth, bacterial counts in milk of early lactation cows were greater compared with those in late lactation cows $(P<0.05)$. Bacterial counts in milk following challenge were similar between early and late lactation $(P>0.05)$ cows in those quarters infused with isolates highly adaptive for in vitro growth. Bacterial counts were greater $(P<0.05)$ in milk from quarters infused with the isolates poorly adaptive for in vitro growth compared with the isolates highly adaptive for in vitro growth on d 2, 3, and 4 for both early and late lactation cows (Figure 1). In early lactation cows, bacterial counts in milk of quarters challenged with isolates poorly adaptive for in vitro growth remained elevated compared with isolates highly adaptive for in vitro growth through d 21 postchallenge $(P<0.05)$. In 

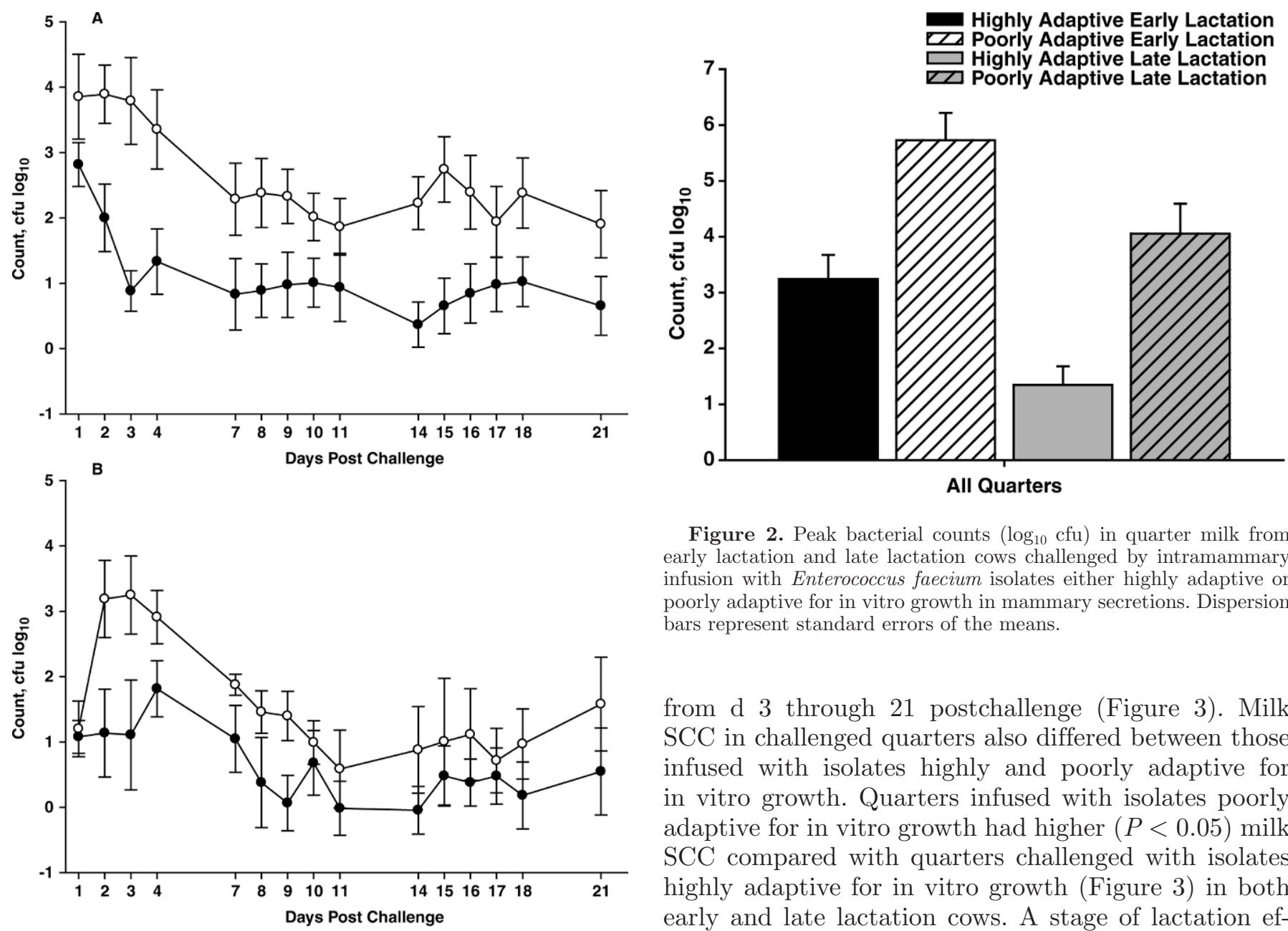

Figure 2. Peak bacterial counts $\left(\log _{10} \mathrm{cfu}\right)$ in quarter milk from early lactation and late lactation cows challenged by intramammary infusion with Enterococcus faecium isolates either highly adaptive or poorly adaptive for in vitro growth in mammary secretions. Dispersion bars represent standard errors of the means.

Figure 1. Bacterial counts $\left(\log _{10} \mathrm{cfu}\right)$ in quarter milk from early lactation (A) and late lactation (B) cows challenged by intramammary infusion with Enterococcus faecium isolates either highly adaptive ( or poorly adaptive $(\bigcirc)$ for in vitro growth in mammary secretions. Dispersion bars represent standard errors of the means.

contrast, bacterial counts in milk of challenged quarters in late lactation cows did not differ between isolates highly and poorly adaptive for in vitro growth from $\mathrm{d} 7$ through 21 postchallenge.

Quarters infused with the isolates poorly adaptive for in vitro growth had significantly higher peak bacterial counts $(P<0.05)$ compared with the isolates highly adaptive for in vitro growth in both early and late lactation cows (Figure 2). Peak bacterial counts of quarters challenged with isolates either highly or poorly adaptive for in vitro growth were higher in milk from early lactation cows compared with late lactation cows $(P<0.05)$.

\section{SCC}

Quarters challenged with E. faecium had higher ( $P$ $<0.05)$ milk SCC than nonchallenged control quarters

from d 3 through 21 postchallenge (Figure 3). Milk SCC in challenged quarters also differed between those infused with isolates highly and poorly adaptive for in vitro growth. Quarters infused with isolates poorly adaptive for in vitro growth had higher $(P<0.05)$ milk SCC compared with quarters challenged with isolates highly adaptive for in vitro growth (Figure 3 ) in both early and late lactation cows. A stage of lactation effect within treatment groups was measured when milk SCC were compared between early and late lactation cows. Milk SCC in nonchallenged control quarters were lower $(P<0.05)$ in early lactation cows compared with late lactation cows. Conversely, in quarters infused with isolates poorly adaptive for in vitro growth, SCC were higher in early lactation cows compared with late lactation cows on $\mathrm{d} 2,3,4,15,16$, and 17 postchallenge. In quarters infused with isolates highly adaptive for in vitro growth, SCC response did not differ between early and late lactation cows $(P>0.05)$.

\section{DISCUSSION}

An intrinsic difference was found in the ability of $E$. faecium to cause IMI in mammary glands of early and late lactation cows. Quarters of early lactation cows were more susceptible to IMI with E. faecium and produced a more pronounced SCC response compared with cows in late lactation. Early lactation cows appear to be at increased risk of disease due to the physiological stress of calving and metabolic disorders associated with high milk production (Suriyasathaporn et al., 2000). Shuster 
et al. (1996) suggested that a low SCC at calving might predispose those animals to severe mastitis. Milk SCC of quarters at challenge were reduced in early lactation cows compared with late lactation cows in the present study. However, the increase in SCC was more rapid the first $4 \mathrm{~d}$ after challenge in early lactation cows compared with late lactation cows. This elevated SCC the first week following challenge during early lactation corresponded to a higher mean bacterial count in early lactation cows compared with late lactation cows. Escherichia coli (Shuster et al., 1996), and endotoxin (Lehtolainen et al., 2003) challenges produced more severe clinical mastitis and enhanced SCC responses in early lactation cows compared with late lactation cows. The results of the current E. faecium challenge trial concur with these previous challenge trials and natural exposure trials (Hogan et al., 1989; Olde Riekerink et al., 2008) that indicate a general heightened susceptibility of cows in early lactation compared with late lactation.

Each E. faecium isolate tested established at least one IMI in both early and late lactation glands, and $88 \%$ of IMI resulted in clinical mastitis. However, isolates poorly adaptive for in vitro growth were more likely to cause an IMI than the isolates highly adaptive for in vitro growth. The E. faecium isolates used for intramammary challenge were selected based on their ability to grow in mammary secretions from dry cows, early lactation cows, late lactation cows, and extended lactation cows (Petersson-Wolfe et al., 2007). The isolates highly adaptive for in vitro growth were able to replicate at a greater rate in secretions from all stages of lactation compared with the bacteriostatic or bacteriocidal growth responses of isolates poorly adaptive for in vitro growth in mammary secretions. The results of the in vitro study were not predictive of in vivo pathogenicity in the current trial because isolates poorly adaptive for in vitro growth isolates were more likely to cause IMI, elevated bacterial counts, and elevated SCC compared with the isolates highly adaptive for in vitro growth. Others have examined the correlation between in vitro growth and in vivo pathogenicity for coliform bacteria (Lohuis et al., 1990; Todhunter et al., 1990). The previous trials suggested that in vitro growth in skim milk was not a suitable predictor for differences in susceptibility following intramammary challenge. Although the previous trials reported a lack of association between in vitro growth and pathogenicity, the results of the current trial yielded a significant inverse relationship between in vitro growth of E. faecium in mammary secretion and in vivo pathogenicity in the mammary glands of early and late lactation cows. The reason for this inverse relationship is conjecture, but a possible

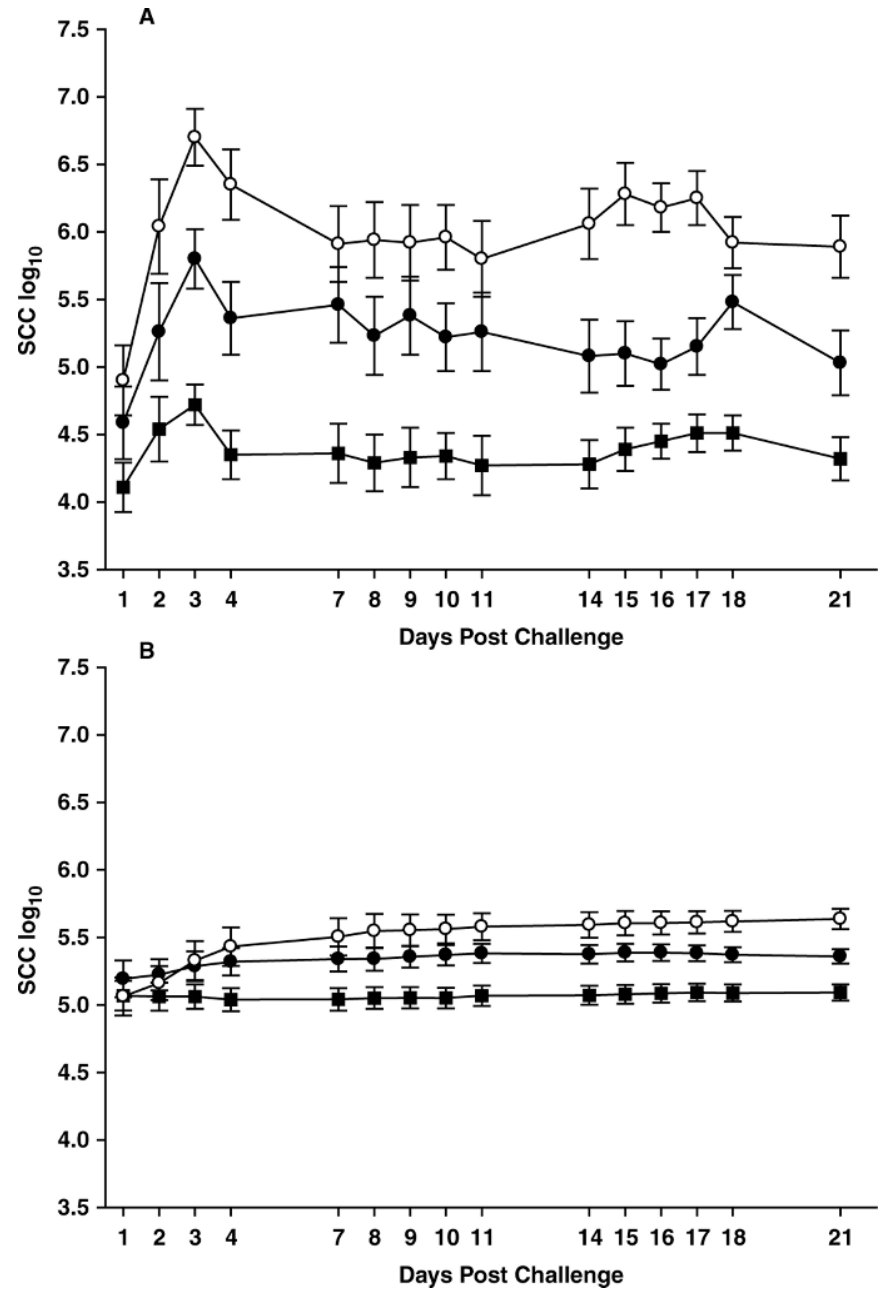

Figure 3. Somatic cell counts in quarter milk from early lactation (A) and late lactation (B) cows challenged by intramammary infusion with Enterococcus faecium isolates either highly adaptive $(\bullet)$ or poorly adaptive $(\bigcirc)$ for in vitro growth in mammary secretions. Uninfused quarters of experimental cows were negative controls (ם). Dispersion bars represent standard errors of the means.

explanation may be related to the in vitro growth conditions used to select isolates including the removal of fat and cells from mammary secretion before the assay. Lohuis et al. (1990) compared E. coli growth in whole milk from mastitic glands to growth in skim milk and suggested that whole milk was a better predictor for in vivo pathogenicity. Removal or alteration of one of the numerous antimicrobial substances in mammary secretion (Reiter, 1978; Craven and Williams, 1985) for in vitro cultures may have contributed to the realized contradiction between in vitro growth responses and intramammary challenge results observed in the current trial. Developing an in vitro assay that could accurately predict in vivo pathogenicity is warranted. The considerable difference between in vitro growth 
and in vivo pathogenicity results observed in the current trial indicates that the conditions utilized for the in vitro growth assay failed to simulate in vivo conditions. The ability to cause IMI in vivo is due in part to pathogenic factors allowing the evasion of host defense mechanisms. This pathogen-contributed effect may not be measureable in vitro.

Enterococcus faecium has historically been grouped with esculin-positive streptococci and other enterococcal species when prevalence data of mastitis surveys and field trials were reported (McDonald and McDonald, 1976; Hogan et al., 1989). The validity of assuming homogeneous pathogenicity among the bacteria classified as "environmental streptococci" is questionable when the results of the current trial are referenced to previous intramammary challenges with Streptococcus uberis. The bacterial counts of E. faecium following intramammary challenge in early lactation cows peaked at d 1 after challenge for isolates both poorly and highly adaptive for in vitro growth, whereas peak SCC responses were delayed until d 3 after challenge. In contrast, early lactation cows challenged by intramammary infusion with a similar inoculum of Strep. uberis by Rambeaud et al. (2003) had peak bacterial counts d 5 after challenge, but SCC responses in infected quarters peaked $2 \mathrm{~d}$ before peak bacterial counts and remained constant through d 7 after challenge. Quarters challenged with E. faecium in the current trial did not display the prolonged lag growth phase in mammary glands observed in Strep. uberis-challenged quarters (Rambeaud et al., 2003). The rapid increase in E. faecium counts after challenge preceded a rapid increase in milk SCC. Corresponding to the increase in milk SCC, a subsequent decline in E. faecium counts from d 4 through 21 was observed. An inverse relationship between neutrophil recruitment and clinical severity has been shown for coliform mastitis (Hill et al., 1979; Vandeputte-Van Messom et al., 1993). Neutrophil influx from the circulation to the mammary gland resulted in bacterial elimination, and the speed at which this process occurs was inversely related to coliform growth (Vandeputte-Van Messom et al., 1993; Shuster et al., 1997). The dynamics of E. faecium growth in the mammary gland and SCC responses after challenge more closely resembled previous results following challenge with E. coli compared with responses after Strep. uberis experimentally induced infections.

In summary, mammary quarters of early lactation cows were more susceptible than those of late lactation cows to IMI caused by E. faecium. In addition, in vitro growth of E. faecium in mammary secretions was inversely related to in vivo pathogenicity in the mammary glands of both early and late lactation cows.

\section{REFERENCES}

Aleksieva, V., and D. Todorov. 1981. Cases of clinical and subclinical mastitis caused by "D" streptococci. Vet. Med. Nauki 18:86-91.

Craven, N., and M. R. Williams. 1985. Defences of the bovine mammary gland against infection and prospects for their enhancement. Vet. Immunol. Immunopathol. 10:71-127.

Devriese, L. A., J. Hommez, H. Laevens, B. Pot, P. Vandamme, and F. Haesebrouck. 1999. Identification of aesculin-hydrolyzing streptococci, lactococci, aerococci and enterococci from subclinical intramammary infections in dairy cows. Vet. Microbiol. 70:8794.

Edwards, D. D. 2000. Enterococci attract attention of concerned microbiologists. ASM News 66:540-545.

Gianneechini, R., C. Concha, R. Rivero, I. Delucci, and J. Moreno Lopez. 2002. Occurrence of clinical and sub-clinical mastitis in dairy herds in the West Littoral Region in Uruguay. Acta Vet. Scand. 43:221-230.

Helie, P., and R. Higgins. 1999. Diarrhea associated with Enterococcus faecium in an adult cat. J. Vet. Diagn. Invest. 11:457-458.

Hill, A. W., J. M. Finch, T. R. Field, and J. A. Leigh. 1994. Immune modification of the pathogenesis of Streptococcus uberis mastitis in the dairy cow. FEMS Immunol. Med. Microbiol. 8:109-117.

Hill, A. W., A. L. Shears, and K. G. Hibbitt. 1979. The pathogenesis of experimental Escherichia coli mastitis in newly calved dairy cows. Res. Vet. Sci. 26:97-101.

Hogan, J. S., V. L. Bogacz, M. Aslam, and K. L. Smith. 1999. Efficacy of an Escherichia coli J5 bacterin administered to primigravid heifers. J. Dairy Sci. 82:939-943.

Hogan, J. S., K. L. Smith, K. H. Hoblet, P. S. Schoenberger, D. A. Todhunter, W. D. Hueston, D. E. Pritchard, G. L. Bowman, L. E. Heider, B. L. Brockett, and H. R. Conrad. 1989. Field survey of mastitis in low somatic cell count herds. J. Dairy Sci. 72:15471556.

Jergens, A. E., F. M. Moore, J. C. Prueter, and P. J. Yankauskas. 1991. Adherent gram-positive cocci on the intestinal villi of two dogs with gastrointestinal disease. J. Am. Vet. Med. Assoc. 198:1950-1952.

Lehtolainen, T., S. Suominen, T. Kutila, and S. Pyorala. 2003. Effect of intramammary Escherichia coli endotoxin in early- vs. latelactating dairy cows. J. Dairy Sci. 86:2327-2333.

Lohuis, J. A., W. Kremer, Y. H. Schukken, J. A. Smit, J. H. Verheijden, A. Brand, and A. S. Van Miert. 1990. Growth of Escherichia coli in milk from endotoxin-induced mastitic quarters and the course of subsequent experimental Escherichia coli mastitis in the cow. J. Dairy Sci. 73:1508-1514.

McDonald, T. J., and J. S. McDonald. 1976. Streptococci isolated from bovine intramammary infections. Am. J. Vet. Res. 37:377-381.

Mehrzad, J., L. Duchateau, and C. Burvenich. 2004. Viability of milk neutrophils and severity of bovine coliform mastitis. J. Dairy Sci. $87: 4150-4162$.

Murray, B. E. 1990. The life and times of Enterococcus. Clin. Microbiol. Rev. 3:46-65.

NNIS Report. 1997. National nosocomial infections surveillance (NNIS) report, data summary from October 1986-April 1997, issued May 1997. Am. J. Infect. Control 25:477-487. PubMed

Olde Riekerink, R. G. M., H. W. Barkema, D. F. Kelton, and D. T. Scholl. 2008. Incidence rate of clinical mastitis on Canadian dairy farms. J. Dairy Sci. 91:1366-1377.

Petersson-Wolfe, C. S. 2006. A study of the occurrence, phenotypic, and genotypic diversity of both in vitro and in vivo growth responses of Enterococcus spp. isolated from bovine origin. PhD Diss. The Ohio State University, Wooster. http://www.ohiolink. edu/etd/send-pdf.cgi/PeterssonWolfe\%20Christina\%20Sonja. pdf?acc_num=osu1153766262

Petersson-Wolfe, C. S., S. L. Wolf, and J. S. Hogan. 2007. In vitro growth of enterococci of bovine origin in bovine mammary secretions from various stages of lactation. J. Dairy Sci. 90:4226-4231.

Rambeaud, M., R. A. Almeida, G. M. Pighetti, and S. P. Oliver. 2003. Dynamics of leukocytes and cytokines during experimentally induced 
Streptococcus uberis mastitis. Vet. Immunol. Immunopathol. 96:193-205.

Reiter, B. 1978. Review of the progress of dairy science: Antimicrobial systems in milk. J. Dairy Res. 45:131-147.

Rivas, A. L., F. W. Quimby, O. Coksaygan, A. Alba, A. Arina, M. J. Arrobas, R. N. Gonzalez, H. O. Mohammed, and D. H. Lein. 2001. Expression of CD3 and CD11b antigens on blood and mammary gland leukocytes and bacterial survival in milk of cows with experimentally induced Staphylococcus aureus mastitis. Am. J. Vet. Res. 62:1840-1851.

Rogers, D. G., D. H. Zeman, and E. D. Erickson. 1992. Diarrhea associated with Enterococcus durans in calves. J. Vet. Diagn. Invest. 4:471-472.

Shuster, D. E., M. E. Kehrli Jr., P. Rainard, and M. Paape. 1997. Complement fragment $\mathrm{C} 5 \mathrm{a}$ and inflammatory cytokines in neutrophil recruitment during intramammary infection with Escherichia coli. Infect. Immun. 65:3286-3292.

Shuster, D. E., E. K. Lee, and M. E. Kehrli Jr. 1996. Bacterial growth, inflammatory cytokine production, and neutrophil recruitment during coliform mastitis in cows within ten days after calving, compared with cows at midlactation. Am. J. Vet. Res. 57:15691575 .

Sladek, Z., D. Rysanek, H. Ryznarova, and M. Faldyna. 2005. Neutrophil apoptosis during experimentally induced Staphylococcus aureus mastitis. Vet. Res. 36:629-643.

Suriyasathaporn, W., C. Heuer, E. N. Noordhuizen-Stassen, and Y. H. Schukken. 2000. Hyperketonemia and the impairment of udder defence: A review. Vet. Res. 31:397-412.

Teixeira, L. M., M. G. Carvalho, M. M. Espinola, A. G. Steigerwalt, M. P. Douglas, D. J. Brenner, and R. R. Facklam. 2001. Enterococcus porcinus sp. nov. and Enterococcus ratti sp. nov., associated with enteric disorders in animals. Int. J. Syst. Evol. Microbiol. 51:1737-1743.

Todhunter, D., K. L. Smith, and J. S. Hogan. 1990. Intramammary challenge of the bovine mammary gland with coliform bacteria during early involution. J. Dairy Sci. 73:1217-1224.

Vandeputte-Van Messom, G., C. Burvenich, E. Roets, A. M. MassartLeen, R. Heyneman, W. D. Kremer, and A. Brand. 1993. Classification of newly calved cows into moderate and severe responders to experimentally induced Escherichia coli mastitis. J. Dairy Res. 60:19-29. 